\title{
RESPUESTAS DEL SISTEMA FINANCIERO CONTRA EL BLANQUEO DE CAPITALES ${ }^{1}$
}

\author{
Begoña San Martín Larrinoa
}

\section{Introducción}

El narcotráfico, actividad delictiva sustentada, junto con otras no menos graves como el tráfico de armas o el terrorismo, en el fenómeno de la delincuencia organizada, ha venido siendo objeto de muy diversas iniciativas que pretenden luchar contra sus devastadores efectos: la degradación y muerte de jóvenes, la corrupción de estamentos públicos y privados e incluso la puesta en peligro de gobiernos y sistemas económicos.

Pues bien, tales actividades delictivas y, en particular, el narcotráfico, se apoyan en una tupida y complicada red económica que tejen a su entorno y cuya desarticulación ha de constituir el objetivo prioritario si se quiere luchar de una manera eficaz contra tales organizaciones hasta lograr su destrucción. La red económica de la que hablamos se construye a partir del fenómeno que se ha venido en denominar blanqueo o lavado de dinero. Por tal podemos entender, de una manera sintética, cualquier procedimiento que permita la introducción de fondos de procedencia ilegal en el circuito monetario oficial, permaneciendo oculto el origen ilícito de éstos.

Como cabe deducir de lo escuetamente afirmado sobre el blanqueo de dinero, las actividades que dan lugar al mismo pueden adoptar formas múltiples y cambiantes, en una metamorfosis que varía en función de las épocas, de las normativas que atacan su constitución y de la política de las autoridades que lo persiguen, ya que, obviamente, el objetivo de los delincuentes es evadirse de tal persecución, continuando e incrementando sus actividades ilegales y los pingües rendimientos de las mismas.

\footnotetext{
1 Comunicación presentada a las Jornadas «Drogas, Desarrollo y Estado de Derecho», Bilbao, octubre 1994.
} 
En razón a la vertiginosa variabilidad del fenómeno del blanqueo de dinero, resulta difícil para los redactores de las normas que luchan contra el mismo adoptar definiciones que sean, por una parte, lo bastante precisas como para responder a las exigencias del Derecho Penal y, por otro lado, lo suficientemente generales como para adaptarse a la cambiante realidad que constituye su esencia. Sin embargo, siendo conscientes de tales dificultades, nos parece fundamental describir de forma breve algunos de los eslabones de esa cadena fraudulenta que da lugar al blanqueo de dinero, esto es, a la entrada en el flujo económico legal de fondos procedentes de actividades delictivas, en este caso del narcotráfico, con ocultamiento de su origen.

Así, en primer lugar, hemos de hablar de la remesa de fondos ilegales al circuito monetario financiero, con el lógico fraccionamiento de las sumas depositadas, que generalmente lo son en efectivo: ésta es su característica principal. Es el dinero de la calle, grandes y voluminosas sumas creadas por billetes pequeños, que se desean convertir en instrumentos monetarios más negociables o bien en haberes que disimulen el origen ilícito. Tal fraccionamiento en la introducción del efectivo tiene como objetivo prioritario evitar los trámites de identificación bancaria que se llevan a cabo en operaciones de cierta importancia.

Una vez introducidos los fondos en el sistema financiero, se produce lo que se ha venido en denominar transformación, que consiste en separar los rendimientos económicos ilícitos de su raíz, mediante la creación de un complejo mecanismo de transacciones financieras que garanticen la desaparición de cualquier vestigio que relacione el dinero con su origen y, en consecuencia, asegure el anonimato de sus verdaderos propietarios.

Dentro de esta descripción sintética del procedimiento de blanqueo, diremos que, finalmente, se lleva a cabo la etapa de integración, esto es, de reintroducción en el circuito legal y bajo una apariencia legítima de los fondos de origen ilícito.

Como es obvio, las técnicas de blanqueo de dinero afectan, de una manera fundamental, a las entidades de crédito y demás instituciones financieras, que son utilizadas por los delincuentes para tal fin, comprometiendo así, de una manera grave, la solidez y estabilidad de la institución o establecimiento afectado y la fiabilidad del sistema financiero en general que pierde, de este modo, la confianza del público, una confianza que, de todos es conocido, resulta esencial para el desarrollo de sus actividades.

Sin embargo, los sujetos que hemos mencionado: entidades de crédito y demás instituciones financieras, no son los únicos que pueden verse afectados por tales actividades fraudulentas que dan lugar al blanqueo de 
dinero, sino que hay otros ámbitos y profesiones que también pueden estarlo. Así podemos mencionar: los casinos y casas de juego, los notarios, abogados, agentes inmobiliarios, tasadores de subastas, comerciantes que operan en el comercio de obras de arte, metales preciosos, etc.

Presentado ya el fenómeno criminal más preocupante de nuestros días: la delincuencia organizada y, en especial, la que se dirige al narcotráfico, sus tupidas redes económicas que la alimentan y sostienen y la actividad del blanqueo de dinero fundamental para las mismas, en la cual pueden verse implicados diversos agentes económicos, dirigimos nuestro estudio hacia el examen de los instrumentos normativos de diversa índole que han surgido a partir de los años ochenta para evitar el lavado de dinero $\mathrm{y}$, en especial, para prevenir la utilización del sistema financiero para tal actividad. Una regulación primordial para entender cómo los intermediarios financieros están modificando sus más esenciales principios de secreto bancario a ultranza y de no ingerencia en las actividades de sus clientes, para pasar a una inevitable actitud colaboradora con las autoridades, si no se quiere caer en el favorecimiento de la delincuencia organizada y más precisamente del narcotráfico, poner en peligro la confianza del público en sus instituciones y entidades y la estabilidad del sistema financiero en su totalidad.

\section{Instrumentos normativos en presencia}

Los instrumentos normativos que serán objeto de nuestro estudio tienen muy variados orígenes y tratan el fenómeno del blanqueo con métodos de diversa índole.

Así, el origen de aquéllos puede estar en un ámbito internacional, nacional o profesional, mientras que sus métodos pueden ser de naturaleza penal, administrativa o incluso de autorregulación ético-profesional.

El ámbito internacional es el que más ha destacado por su producción normativa en contra del blanqueo de dinero y a favor de la prevención de la utilización del sistema financiero para tal fin, pues no debemos olvidar que esta actividad de blanqueo de capitales se efectúa, sobre todo, en un contexto internacional que por su extensión y variabilidad permite encubrir más fácilmente el origen delictivo de los fondos.

En un orden cronológico, podemos mencionar los siguientes textos normativos con origen internacional:

—La Recomendación R (80) 10 del Comité de Ministros del Consejo de Europa del 27 de junio de 1980, relativa a las medidas a adoptar contra la transferencia y ocultación de capitales de origen criminal. 
- La Convención de Naciones Unidas, más conocida como Convención de Viena de 19 de diciembre de 1988, concerniente al tráfico ilícito de estupefacientes y sustancias sicotrópicas.

- La Declaración de Principios sobre la prevención de la utilización del sistema bancario para el blanqueo de fondos de origen criminal, dictada en Basilea en diciembre de 1988 por el Comité de Reglas y Prácticas de Control de las operaciones bancarias, formado por los representantes de los bancos centrales y de las autoridades supervisoras de los países miembros del Grupo de los 10 y de Luxemburgo.

-El informe y las 40 recomendaciones hechas en París en febrero de 1990 por el denominado Grupo de Acción Financiera (GAFI), creado en 1989 por decisión de los jefes de Estado y de Gobierno de los 7 países más industrializados, junto con el presidente de la Comisión de las Comunidades Europeas. En tal Grupo participan no sólo tales sujetos originarios sino 8 Estados más entre los que se encuentra España.

- La Convención del Consejo de Europa relativa al blanqueo, al descubrimiento, al embargo y a la confiscación de los productos del delito, adoptada en Estrasburgo el 8 de noviembre de 1990.

— La Directiva 91/308 del 10 de junio, dictada por el Consejo de las Comunidades Europeas y que concierne a la prevención de la utilización del sistema financiero para el blanqueo de capitales.

Este cuerpo normativo emanado de organismos internacionales y supranacionales, y su generación en tan corto período de tiempo (años 1988 a 1991 principalmente), evidencian, de una manera definitiva, la preocupación existente en tales ámbitos por el fenómeno del blanqueo o lavado de dinero.

Sin embargo, de la enumeración de textos normativos que hemos efectuado se desprende que, por una parte, éstos no afectan a todos los Estados del mundo y, por otro lado, que su fuerza jurídica es enormemente desigual. De entre ellos y por la trascendencia que respecto a nuestro país tiene, es de destacar la Directiva 91/308 de la Comunidad Económica Europea que ha sido transpuesta al ámbito normativo español a través de la Ley 19/1993 de 28 de diciembre, sobre determinadas medidas de prevención del blanqueo de capitales. Igualmente destacan, en parecida labor de unificación internacional en la lucha contra el blanqueo, las Recomendaciones del GAFI que han sido dictadas con vocación de ser integradas en las leyes nacionales, no sólo de los países participantes, sino de otros terceros que se acojan a ellas espontáneamente. 
De una manera sistemática, en cuanto a las características que presentan los textos normativos anteriormente citados, diremos, en primer lugar, que la Recomendación del Consejo de Europa de 1980, precursora de los demás textos internacionales en la materia de que tratamos, debe su existencia a la preocupación que se generó en muchos países por la creciente ola terrorista que producía importantes sumas de dinero en metálico, cuyo blanqueo resultaba imprescindible para los delincuentes.

A esta Recomendación le seguirían los demás instrumentos jurídicos que a finales de los años ochenta y principios de los noventa se promulgarían como armas para luchar contra el flujo económico procedente del tráfico ilícito de drogas. Así, la Convención de Viena contempla de una manera global el fenómeno, no limitándose a la lucha contra el blanqueo de dinero y a la privación, en definitiva, del producto económico del narcotráfico, sino dirigiéndose también a lograr de los Estados la represión penal del tráfico de drogas o de los actos de favorecimiento de éste.

Algo distinta fue la motivación de la Declaración de Principios del Comité de Basilea de 1988, afirmándose en el mismo que las autoridades de control bancario «no pueden permanecer indiferentes ante la utilización de los bancos por parte de los delincuentes», sino que han de fomentar el respeto de las reglas de deontología por las entidades bancarias y otras instituciones financieras. Para tal fin, llegan a la consecución de este acuerdo internacional donde se proclaman unos principios deontológicos que exhortan «a la dirección de los bancos a establecer procedimientos eficaces para asegurarse de conocer la identidad de toda persona que trate con su institución, para desanimar la realización de operaciones de apariencia ilegal y para conseguir la cooperación con las autoridades encargadas del cumplimiento de la ley».

Las Recomendaciones del GAFI o Grupo de Acción Financiera, de 1990, resultan de una combinación de la motivación represiva que anima la Convención de Viena y de la preventiva que está en el origen de la Declaración de Basilea. Así, tales Recomendaciones se dirigen a mejorar, fundamentalmente, los sistemas jurídicos nacionales de lucha contra el blanqueo de capitales, a reforzar el papel del sistema financiero en tal lucha y a impulsar la cooperación internacional en la misma.

Por su parte, la Convención del Consejo de Europa de 1990 se presenta con unas armas de índole represiva frente al lavado de dinero, combatiendo el blanqueo a través del imprescindible descubrimiento, embargo y confiscación de los productos delictivos. Se inserta, por tanto, en la búsqueda de una política penal común, para lo cual considera que un método moderno y eficaz de lucha contra la criminalidad grave es, precisamente, privar al delincuente de los rendimientos provenientes de tales delitos. 
Por su parte, la Directiva comunitaria de 10 de junio de 1991 hunde sus raíces en las anteriores normativas y muy especialmente en algunas Recomendaciones del GAFI y considera que «el blanqueo de capitales tiene una influencia evidente sobre el desarrollo del crimen organizado en general y del tráfico de estupefacientes en particular», por lo que la creciente toma de conciencia de la necesidad de luchar contra el mismo, «constituye (según afirma) uno de los medios más eficaces de combatir este tipo de actividad delictiva, que representa una amenaza especial para las sociedades de los Estados miembros».

Además de propugnar de una manera prioritaria las medidas penales dentro de los Estados y la cooperación internacional, dedica su articulado a la fundamental prevención de la utilización del sistema financiero para el blanqueo de capitales.

Como hemos visto, todos los textos internacionales señalados coinciden en expresar, de una manera o de otra, que la lucha contra el blanqueo ayuda a combatir la criminalidad organizada subyacente, que necesita de él para ser rentable.

Por otro lado, es afirmación generalizada en tales normativas y recomendaciones que el blanqueo se debe combatir porque el mismo despliega sus negativos efectos, tanto sobre el sistema financiero como sobre la economía, la sociedad y el Estado. Además, en razón a su naturaleza esencialmente internacional, la lucha contra el blanqueo precisa de una estrecha colaboración de esta índole, para cuya consecución es necesaria, de una manera ineludible, la armonización de las normas nacionales. Un objetivo que subyace en todos los textos internacionales de una u otra procedencia hasta aquí relacionados.

Sin embargo, no podemos dejar el examen de tales textos sin detenernos en algo fundamental y que constituye el objeto de nuestro trabajo: las medidas que se propugnan desde los mismos para evitar el lavado de dinero. Unas medidas a adoptar tanto por los Estados en sus normas internas como por parte de los operadores financieros y demás profesionales susceptibles de ser utilizados para el referido blanqueo de fondos. La adopción de las medidas a que nos vamos a referir por parte de tales operadores económicos no debe estar motivada tan sólo por el cumplimiento de normas imperativas emanadas de instrumentos jurídicos, sino que ha de ser fruto de unos principios de comportamiento basados en la ética y en la dignidad de la respectiva profesión o actividad financiera. Así, respecto a las medidas a adoptar, se propugnan las siguientes:

- La reducción y el control de las operaciones económicas llevadas a cabo en metálico.

Como destacábamos al principio de nuestra exposición, en el blanqueo de capitales existe una primera etapa de introducción en las arterias financieras legales de enormes cantidades de dinero en efectivo. 
El grupo GAFI, a este respecto, destaca la importancia de poner trabas al blanqueo en su raíz, por medio de limitar el uso del dinero en metálico a través de técnicas modernas y seguras de gestión de fondos. Sin embargo, como tal uso no puede ser eliminado en su totalidad, se propugna el control que del mismo se haga. De este modo, se aboga por el establecimiento de un sistema por medio del cual los bancos y otras instituciones financieras de depósito declaren todas las transacciones nacionales e internacionales en efectivo, por encima de un cierto importe, a una agencia central, siendo accesible tal información para las autoridades competentes en la lucha contra el blanqueo de dinero y en el ámbito estricto de tal objetivo.

-Obligación de conocer bien a los clientes.

Se trata de una regla elemental para cualquier profesión expuesta al riesgo de ser utilizada para el blanqueo de dinero. Esta recomendación estuvo prevista desde los primeros instrumentos jurídicos internacionales que hemos examinado. Así, el Consejo de Europa en 1980 ya hablaba de comprobar la identidad de los que realizan operaciones bancarias, sobre todo, aperturas de cuentas, transacciones en metálico de cierta envergadura y alquiler de cajas de seguridad.

El GAFI, por su parte, extiende la obligación de verificar la identidad a los poseedores de derechos económicos por cuenta de los cuales pueden actuar los clientes de las entidades financieras.

-Examen detenido de cualquier operación que se salga de lo común y que no tenga una causa económica lícita aparente, en especial las transacciones con países que no apliquen debidamente las recomendaciones del GAFI.

-Cooperación con las autoridades.

Esta es otra obligación esencial impuesta por los textos normativos internacionales hasta aquí examinados. La asunción de esta obligación por parte de las entidades financieras tiene un efecto preventivo en la medida en la que muchos delincuentes pueden verse disuadidos de acudir a las mismas para intentar el blanqueo, debido al riesgo de denuncia y sirve, por otro lado, para la detección y represión de tales actividades. Esta doble utilidad ya se desprendía de la Recomendación del Consejo de Europa de 1980.

La cooperación mencionada conlleva en sí un estrechamiento del ámbito del secreto bancario que, lógicamente, ha de levantarse para impedir que, tras el mismo, se oculten los rendimientos de los delitos.

Por otro lado, se establece que las instituciones financieras declaren rápidamente sus sospechas a las autoridades competentes sin alertar a sus clientes si piensan que los fondos que les entregan provienen de actividades delictivas. En contrapartida a esta colaboración, se exime a tales en- 
tidades, a sus directivos y empleados de responsabilidad alguna resultante de una información efectuada de buena fe.

Para la consecución de tal colaboración, se insta a dichas instituciones a potenciar su auditoría interna, a asegurar la información y formación del personal en las normas y principios que luchan contra el blanqueo y a poner en marcha procedimientos específicos de archivo y conservación de documentos identificativos y de aquellos relacionados con las operaciones que efectúen.

Por otra parte, en las normas internacionales contempladas, se menciona como principio fundamental para evitar la utilización del sistema financiero para el blanqueo, la instauración de «una cultura de empresa» que haga fracasar cualquier tentación en pos de dicho blanqueo. Esta «cultura» es el resultado indudable de una formación apropiada y de una actitud de respeto a las leyes, a las reglas de deontología y a la ética profesional.

Sin embargo, las normativas hasta aquí descritas que obligan, sobre todo, a las instituciones financieras, tienen que completarse con la actuación de las autoridades que ejercen funciones supervisoras sobre las profesiones amenazadas por el blanqueo. A ellas incumbe velar para que dichos operadores respeten las reglas, tanto de índole normativa como deontológica, asegurar que disponen de medidas internas para evitar el blanqueo de capitales y ayudar a tales entidades y profesionales a detectar los comportamientos sospechosos y a formar a su personal.

Otra labor preventiva de particular importancia que concierne a las autoridades y organismos de vigilancia de las instituciones financieras consiste en evitar que los delincuentes o sus cómplices puedan tomar el control o una participacion significativa en una institución de la citada índole.

\section{Normativa española relacionada con la represión del blanqueo de dinero o prevención de la utilización del sistema financiero para dicho fin}

Examinado el abanico normativo internacional que se ha dictado contra el blanqueo o lavado de dinero, dirigimos ahora nuestra atención hacia las regulaciones que en un plano interno se han puesto en vigor para reprimir, unas veces penalmente y otras desde el ámbito administrativo, tal blanqueo de fondos. En este contexto, es de destacar, igualmente, la adopción de una autorregulación, a modo de código de conducta, que inspirada en los textos internacionales han dictado en nuestro país la Asociacion de Banca Española y la de Cajas de Ahorro. 
En la lucha contra el blanqueo de dinero y en cuanto al ámbito penal, la adaptación a las obligaciones asumidas internacionalmente por España comenzó con la Ley Orgánica 1/88 de 24 de marzo que dio lugar al artículo 546 bis f) del Código Penal, donde se contempla una modalidad específica de receptación en relación con los artículos 344 a 344 bis b) referidos a los delitos contra la salud pública.

Por su parte, la Ley Orgánica 8/92 de 23 de diciembre asumió, casi literalmente, los tipos delictivos insertos en la Convención de Viena de 1988, con lo que completó la descripción que en nuestro derecho punitivo se hacía del blanqueo de dinero, introduciendo los artículos 344 bis h) y 344 bis i) extendiéndose el primero a formas de comisión del blanqueo tanto dolorosas como culposas por negligencia o ignorancia inexcusables, figura ésta que podría ser aplicable a aquellos intermediarios económicos que, bajo tales premisas, realizasen actos de participación en actividades de conversión o transferencia de bienes que tuvieran por objeto ocultar o encubrir el origen ilícito de éstos.

Finalmente, la Ley 19/93 de 28 de diciembre, sobre determinadas medidas de prevención del blanqueo de capitales, ha transpuesto la Directiva del Consejo de las Comunidades Europeas de 10 de junio de 1991 y, de acuerdo con lo previsto en su artículo 1, extiende el ámbito de aplicación no sólo al blanqueo relacionado con el tráfico de estupefacientes, drogas tóxicas o sustancias sicotrópicas, sino también al relativo a las actividades terroristas y a la delincuencia organizada. Esta ampliación del ámbito objetivo conlleva la necesidad de armonizar, coherentemente, nuestro Código Penal, tipificando la actividad del blanqueo de bienes que tengan un origen delictivo más general que el propio tráfico de estupefacientes.

En cuanto a las obligaciones administrativas contenidas dentro de la Ley 19/93 de 28 de diciembre sobre determinadas medidas de prevención del blanqueo de capitales, diremos que las mismas están dirigidas, primordialmente, a las personas y entidades que integran el sistema financiero, aunque en la citada Ley se prevea un ámbito subjetivo aún más amplio. Las principales obligaciones que se imponen a sus destinatarios son las de información y colaboracion con las autoridades, concretadas en:

- La identificación de la clientela y de las personas por cuya cuenta actúa ésta.

-El examen, con particular atención y con independencia de su cuantía, de toda operación que pueda estar particularmente vinculada con el blanqueo de capitales.

- La conservación, durante un período mínimo de cinco años, de los documentos acreditativos de la identidad de los sujetos y de la realizacion de las operaciones. 
- La colaboración con el Servicio Ejecutivo de la Comisión de Prevención del Blanqueo de Capitales e Infracciones Monetarias. Dicha colaboración abarca los siguientes aspectos: la comunicación por iniciativa propia de cualquier hecho u operación respecto al que exista indicio o certeza de que está relacionado con el blanqueo de dinero y la entrega de aquella información que el Servicio Ejecutivo requiera. Estas comunicaciones efectuadas de buena fe no constituirán, según indica la Ley, violación de las restricciones que sobre revelación de información pudieran haberse impuesto por vía contractual o por cualquier disposición legal o reglamentaria y no implicarán para los sujetos obligados a facilitar tal información, sus directivos o empleados, ningún tipo de responsabilidad.

- Abstenerse de ejecutar cualquier operación sospechosa sin haber efectuado, previamente, la comunicación a dicho Servicio Ejecutivo.

- No revelar al cliente ni a terceros que se han transmitido las referidas informaciones o que se está examinando, a estos efectos, alguna operación.

-Establecer procedimientos y órganos adecuados de control interno y de comunicación, a fin de prevenir la realización de operaciones relacionadas con el blanqueo de capitales.

- Adoptar las medidas oportunas para que los empleados de las entidades conozcan las exigencias de la Ley de que tratamos y establecer planes de formación y cursos dirigidos a capacitarles para detectar las operaciones conectadas con el blanqueo de dinero y los procedimientos a seguir en tales casos.

El incumplimiento de estas obligaciones de ámbito administrativo puede conllevar la correspondiente sanción de tal índole, unas sanciones que, por otro lado y según la directiva 91/308, se dejan a la concreción de cada Estado miembro. En nuestra Ley oscilan entre la amonestación privada o pública y multas para las entidades implicadas de importes que pueden alcanzar, entre un millón de pesetas, porcentajes del 5\% de los recursos propios de la entidad, del duplo del contenido económico de la operación, o bien de una cuantía de 250 millones de pesetas. Estas sanciones, sin perjuicio de las también previstas en la Ley respecto a quienes ejerzan cargos de administración o dirección en la entidad y sean responsables de las actuaciones infractoras a título de dolo o culpa.

Por otro lado, resulta fundamental destacar de esta normativa su Disposición Adicional Primera, que señala que «aun cuando no lo exijan las correspondientes leyes o reglamentos locales, las entidades españolas sujetas a la presente Ley velarán para que sus sucursales y filiales en el ex- 
tranjero tengan establecidos procedimientos internos para prevenir e impedir la realización de operaciones relacionadas con el blanqueo de capitales», afirmando que cuando las leyes o reglamentos locales impidan o hagan ineficaces tales procedimientos, las entidades financieras lo comunicarán al Servicio Ejecutivo quien, a su vez, lo transmitirá a la Comisión de Prevención del Blanqueo de Capitales para que adopte lo que considere conveniente a estos efectos.

Por último y dentro de la normativa establecida en nuestro país, esta vez con carácter de código de actuación y de ética profesional, hemos de mencionar las normas adoptadas en julio de 1990 para la prevención del blanqueo de dinero de origen criminal, por la propia banca privada, integrada por la Asociación Española de tal Banca Privada AEB y por las cajas de ahorro insertas en la Confederación Española de las mismas. Estas organizaciones, junto con el Banco de España, establecieron la forma de desarrollar la Declaración de Basilea mediante unas normas de actuación y de ética profesional de obligada observancia para las entidades de crédito y que son adicionales e independientes de cualquier otra obligación legal que exista. Tales normas contemplan la pormenorización de las clásicas obligaciones de identificación de clientes y cooperación con las autoridades encargadas del cumplimiento de las leyes, así como las derivadas de la observancia estricta de éstas, de los reglamentos que las desarrollen y de rigurosas reglas deontológicas que afecten a las transacciones financieras.

Finalmente, se reiteran las obligaciones de informar y formar a los empleados de las entidades de crédito y potenciar la auditoría interna de las instituciones, una auditoría que controle eficazmente el cumplimiento de las normas cuyo respeto se propugna.

\section{Conclusiones}

Como hemos podido apreciar, la lucha contra el blanqueo de dinero procedente de actividades delictivas como el narcotráfico ha iniciado su andadura por medio de instrumentos normativos internacionales que han tenido siempre, como objetivo prioritario, la unificación y coherencia de las legislaciones internas de los diferentes países. Una unificación que aún estamos lejos de conseguir y cuya carencia constituye el más firme apoyo para los que tratan de lavar los capitales de origen ilegal.

Pero la unificación de legislaciones es sólo una parte de ese cerco a construir en torno al fenómeno del lavado de dinero de origen criminal, el otro lo constituye la consecución de una estrecha cooperación internacional entre las autoridades judiciales y administrativas de los diferentes 
países, ya que los delincuentes en su actividad de blanqueo precisan de tal escenario internacional.

Por último y en cuanto al papel preventivo de las instituciones financieras en este ámbito, hemos de hacer hincapié en que las mismas han de ser conscientes de la importancia de su labor, tanto en lo que corresponde a su colaboración en la lucha contra el blanqueo de dinero y en definitiva contra el crimen organizado, como en lo que se refiere a la tarea de preservar la solidez, estabilidad y buen nombre del sistema financiero en su totalidad y la confianza del público en el mismo, que puede tambalearse si tal actitud colaboradora no se lleva a cabo.

Ejercer adecuadamente esta tarea preventiva por parte de las instituciones financieras confiere un carácter éticamente justificable a su razón de ser y se muestra como una verdadera cuestión de identidad profesional.

\section{Bibliografía}

ABA (1991): «Spotting and handling suspicious transactions», ABA Journal, January 1991, 26-28.

BERNARD, F. (1990): «Les banques contre le blanchiment d'argent». Eurepargne, 49, 17-20.

CABRILlac, M. y Bernard, T. (1990): «Banques et opérations de banque: Législation et réglementation», Revue trimestrielle de Droit Comparé, 43, 615-616.

EscribANo, M. (1987): «Análisis económico de la drogadicción» en el Libro Blanco de las Drogodependencias en Euskadi: II Congreso Mundial Vasco, Gobierno Vasco, Vitoria-Gasteiz, 91-110.

Espín, C. (1991): «Desarrollo comunitario de normas tendentes a impedir la utilización del sistema financiero para el blanqueo de capitales», Revista de Derecho Bancario y Bursátil, 41, 203-206.

EsPíN, C. (1991): «Guía contra el blanqueo de dinero de la Federación de Banca de la Comunidad Europea», Revista de Derecho Bancario y Bursátil, 44, 1.174-1.176.

GuILL, J. (1994): «Législation internationale et Luxembourgeoise sur le blanchiment d'argent» en Droit bancaire et financier au Grand-Duché de Luxembourg, Larcier, S.A., Bruxelles, 551-558.

SÁNCHEZ, M.C. (1992): «Procedimiento urgente para limitar el uso de dinero y de títulos al portador en las transacciones con el fin de prevenir la utilización del sistema financiero para el blanqueo de fondos en Italia», Revista de Derecho Bancario y Bursátil, 45, 300-301.

SÁNCHEZ-CALERO, J. (1990): «Diversas iniciativas en contra del "blanqueo de dinero" a través del sistema financiero», Revista de Derecho Bancario y Bursátil, 37, 201-203.

SÁNCHEZ-CALERO, J. (1990): «Nuevas medidas en contra del blanqueo de dinero», Revista de Derecho Bancario y Bursátil, 39, 714-716. 
SÁNCHEZ-CALERo, J. (1991): «Aprobada la propuesta de Directiva sobre el blanqueo de capitales», Revista de Derecho Bancario y Bursátil, 42, 500-503.

SÁnCHEZ-CALERo, J. (1991): «Francia: Nueva Ley en materia de blanqueo de capitales», Revista de Derecho Bancario y Bursátil, 43, 886-888.

SÁNCHEZ-CALERO, J. (1992): «Nuevas iniciativas para la prevencion del "blanqueo" de dinero a través del sistema financiero», 45, 294-295. 